\title{
CORRECTIONS
}

\section{Publisher Correction: Engineering and physical sciences in oncology: challenges and opportunities}

Michael J. Mitchell, Rakesh K. Jain and Robert Langer

Nature Reviews Cancer (2017) https://doi.org/10.1038/nrc.2017.83

Published online 13 October 2017

The article as originally published incorrectly cited reference 31 in the legend for figure 7.

The correct reference should have been reference 132 (Angelo, M. et al. Multiplexed ion beam imaging of human breast tumors. Nat. Med. 20, 436-442 (2014)).

https://doi.org/10.1038/s41568-018-0072-x I Published online 18 October 2018 